37. Верещагина И.В. Ранний неолит на Северной Двине // Археологические памятники Печоры, Северной Двины и Мезени: материалы по археологии Европейского Северо-Востока. Вып. 6 / отв. ред. В.С. Стоколос. Сыктывкар: Коми филиал АН СССР, 1977. C. 31-36.

38. Карманов В.Н. Стоянка Зубово - памятник с накольчатой керамикой на Мезени (Архангельская обл.) // Проблемы изучения эпохи первобытности и раннего средневековья лесной зоны Восточной Европы: к 60-летию А.В. Уткина. Вып. 4 / под ред. Е.Л. Костылёвой и В.А. Аверина. Иваново: Издатель Ольга Епишева, 2015. С. 66-71.

39. Косинская Л.Л. Неолитическая стоянка Кочмас на Нижней Вычегде // Неолитические памятники Урала: сб. науч. тр. Свердловск: УрО АН СССР, 1991. С. 4-20.

40. Зеленский В.С. Памятник эпохи бронзы Синегорье на Цильме // Первобытные и средневековые древности европейского северо-востока: материалы по археологии европейского северо-востока. Вып. 19
/ отв. ред. А.В. Волокитин. Сыктывкар: ИЯЛИ Коми НЦ УрО РАН, 2015. С. 39-52.

41. Цетлин Ю.Б. Керамика. Понятия и термины историко-культурного подхода. М.: ИА РАН, 2017. $346 \mathrm{c}$.

42. Грязнов М.П. Техника графической реконструкции формы и размеров глиняной посуды по фрагментам // Советская археология. М.-Л.: Изд-во академии наук СССР, 1946. С. 306-318.

43. Цетлин Ю.Б. Понятие качества для анализа объема сосудов // Краткие сообщения института археологии. Вып. 239. М.: Языки славянской культуры, 2015. C. 393-408.

44. Косинская Л.Л. Ранняя гребенчатая керамика в неолите Зауралья // Уральский исторический вестник. 2014. № 2 (43). С. 30-40.

Исследование выполнено в рамках научно-исследовательской работы «Археологическое наследие европейского северо-востока России: выявление, научное описание и систематизация", №ГР 0417-2015-0031.

\title{
CERAMIC WARE IN THE CULTURE OF MOBILE FORAGERS OF THE EXTREME NORTH-EAST OF EUROPE
}

(C) 2018

Karmanov Victor Nicolaevich, candidate of historical sciences,

head of Preservation and Popularization of Archaeological Heritage Sector

Institute of Language, Literature and History

of Komi Scientific Centre of the Ural Branch of the Russian Academy of Sciences (Syktyvkar, Russian Federation)

Abstract. In the paper the author summarized and systematized the initial data on ceramic ware of the Neolithic and Eneolithic of the Extreme north-east of Europe. He analyzed information about the archaeological contexts of ceramics, its quantitative (number of capacities in each complex) and qualitative (shape, proportionality and volume of vessels) characteristics. Critical analysis is used to assess the possibilities of available materials to extract information. As a result, the dynamics of quantitative and qualitative parameters of ceramic ware during the VI - first half of II millennium $\mathrm{BC}$ was traced. Its cultural and chronological features are determined as well. It is established that in the first half of the $\mathrm{V}$ millennium $\mathrm{BC}$ ceramics in the form of sets of vessels of different volumes and kinds becomes an integral part of the daily life of the hunters of the region. According to their lifestyle, the demand for ceramics was limited: the average number of simultaneously used vessels on average 3-4 containers per context. In this case, the simplest forms (round-bottomed pots with volumes up to 25 liters and bowl-shaped dishes up to 2,5 liters) predominate. Ceramic traditions presented in the region are associated with cultures that originate in different adjacent areas of the forest zone of Eastern Europe and Western Siberia, so the universality of the customary forms, volumes and, probably, the ways of using ceramic dishes, is universally accepted. The data obtained can be used as materials for the development of the problem of the distribution of early ceramics, for assessing the role and determining the place of it in the material culture of the prehistoric population.

Keywords: prehistoric culture; archaeology; archaeological data; archaeological context; site; habitat; hunting camp; settlement; subterrain dwelling; assemblage; hearth; Neolithic; Eneolithic; extreme north-east of Europe; ceramics; ceramic ware; form of vesells; volume of capacity.

УДК 903.01

Статья поступила в редакцию 19.06 .2018

\section{КОСТЯНОЙ И РОГОВОЙ ИНВЕНТАРЬ ПАМЯТНИКОВ РАННЕГО НЕОЛИТА ДНЕПРО-ДВИНСКОГО МЕЖДУРЕЧЬЯ: ТЕХНОЛОГИЧЕСКИЕ И ФУНКЦИОНАЛЬНЫЕ ОСОБЕННОСТИ, КОНТЕКСТ}

(C) 2018

Малютина Анна Андреевна, младший научный сотрудник экспериментально-трасологической лаборатории Институт истории материальной культуры РАН (2. Санкт-Петербург, Российская Федерация)

Аннотация. В данной статье представлены результаты трасологического исследования костяного и рогового инвентаря, полученного в результате раскопок памятников раннего неолита на территории ДнепроДвинского междуречья. Подобное исследование проводится впервые для данной категории археологического материала. Для анализа было отобрано 27 предметов из кости, рога и зубов, происходящих с двух памятников Сертейского микрорегиона - Сертея X и Рудня Сертейская. Хорошая сохранность изделий позволила изучить макро- и микроследы, связанные с технологией обработки сырья и получения изделий, способы ис- 
пользования готовых изделий утилитарного и неутилитарного характера. Были выделены следующие категории изделий: ножи, проколки, подвески, наконечники острог, наконечники стрел, зубчатые острия, заготовки, фрагменты изделий со следами обработки. Полученная информация соотнесена с другими материалами памятников - керамикой, каменными артефактами, предложена хозяйственно-культурная характеристика поселений в целом. Время появления керамических традиций в верховьях Западной Двины относится к 7 тыс. до н.э. Самые ранние керамические традиции объединены в сертейскую археологическую культуру. Позднее, в материалах стоянок раннего неолита прослеживается влияние ранненеолитических культур Восточной Прибалтики. В результате на территории Подвинья формируется руднянская культура раннего неолита.

Ключевые слова: ранний неолит; сертейская культура; руднянская культура; Днепро-Двинское междуречье; нарвская культура; трасологический анализ; выбор сырья; технология обработки; первичная обработка; заготовка; вторичная обработка; макроследы; микроследы; функция; типология; категория; реконструкция; древняя охота и рыболовство.

Регион Днепро-Двинского междуречья на данный момент является одним из наиболее изученных на территории лесной зоны Восточной Европы. Планомерными исследованиями археологической экспедиции Государственного Эрмитажа (с 1964 г. руководитель экспедиции А.М. Микляев; с 1993 г. - А.Н. Мазуркевич) были выявлены и исследованы памятники от верхнего палеолита до эпохи раннего металла. Исходя из анализа приуроченности памятников каменного века к тем или иным физико-географическим единицам (озёрной котловине, отрезку течения реки) А.М. Микляев разделил регион на «археологические микрорайоны»: Усвятский, Сертейский, Сенницкий, Удвятский и Жижицкий [1, с. 33]. На сегодняшний день памятники раннего неолита известны для всех микрорегионов Днепро-Двинского междуречья, за исключением Жижицкого. Мы же в своей статье остановимся на двух памятниках Сертейского микрорегиона - Сертея X и Рудня Сертейская.

Как показали исследования последних лет, керамическая традиция впервые появляется в верховьях Западной Двины в 7 тыс. до н.э. и связана она, вероятно, с миграциями небольших групп людей или «миграциями идей» [2] с южных областей Восточной Европы (сначала с территории Нижнего Дона, а затем с региона Нижней Волги) [3, с. 80]. Эти «движения» нашли отражение в керамическом материале, в технологии изготовления посуды, её морфологии и украшении, что, в свою очередь, стало основой для выделения «керамических фаз» [4; 5]. Самые ранние свидетельства использования керамической посуды на территории Днепро-Двинского междуречья объединены в сертейскую археологическую культуру, которая имеет датировки 7000-5300 л. до н.э. [6]. С другой стороны, позже, на территории Подвинья, с запада, появляется новое население, связанное с ранненеолитическими восточноприбалтийскими культурами. В результате контактов и влияниям со стороны местной сертейской культуры происходит формирование руднянской культуры. Время бытования руднянской культурной традиции - конец 6 тыс. до н.э. - вторая четверть 5 тыс. до н.э. [6]. Аналогии керамическому материалу можно найти на синхронных ранненеолитических памятниках Латвии и Эстонии - Звидзе, Оса, Акали [3, с. 82].

Помимо керамического материала, на стоянках раннего неолита была обнаружена интересная коллекция каменного инвентаря - орудий и отходов их производства. На двух памятниках этого периода были также найдены изделия из дерева, кости, рога. Сохранность изделий из органических материалов обусловлена естественной консервацией культурных отложений во влажных почвах.
В этой статье мы бы хотели остановиться на особенностях костяного и рогового инвентаря. Благодаря хорошей степени сохранности внешней поверхности изделий из кости, рога, зубов, нам удалось проанализировать их с точки зрения экспериментальнотрасологического метода, суть которого заключается в изучении на макро- и микроуровнях следов изготовления - следов, образовавшихся в результате работы с тем или иным материалом [7-9]. Анализ технологических следов позволяет выделять следы первичной и вторичной обработки. Первичная обработка заключается в получении заготовки изделия. Можно выделить несколько наиболее распространённых приёмов получения заготовок орудий из кости и рога: раскалывание (дробление) посредством тяжёлого предмета, расщепление кости по её длине либо ширине по предварительно вырезанным пазам, расщепление по трещинам, поперечное разламывание при сгибании $[10 ; 11]$. На этапе получения искомых орудий заготовка может подвергаться строганию, скоблению, сверлению, шлифовке и полировке $[12 ; 13]$. Все эти операции оставляют на поверхности предмета отличные друг от друга технологические следы. Данные следы, следы вторичной обработки, как правило, накладываются на следы от получения заготовки, иногда частично, а иногда и полностью уничтожая их. В связи с этим нахождение на памятнике не только готовых изделий, но и предметов, сохранивших следы различных этапов формообразования, чрезвычайно важно для восстановления всей технологической цепочки. Другой необходимой частью метода является изготовление экспериментальных реплик орудий из кости и рога и использование их в различных хозяйственных операциях. Автором статьи были получены образцы технологических и функциональных макро- и микроследов (на экспериментальных орудиях), которые явились эталонами для сравнения с археологическими образцами. Наша статья посвящена результатам трасологического анализа изделий из кости, рога и зубов эпохи раннего неолита, выполненного для этого материала впервые. Полученная информация по технологии изготовления и использования костяного и рогового сырья соотнесена с особенностями памятников раннего неолита Днепро-Двинского междуречья, с их хозяйственно-культурной атрибуцией в целом. Но сначала несколько слов о самих памятниках.

\section{История изучения}

В 1983 г. в пойменном торфянике речки Сертейки (Смоленская обл., Велижский р-н) была обнаружена многослойная стоянка Рудня Сертейская. Комплексные исследования памятника велись в 1983- 
1986 гг. (1983 г. по 1984 г. руководитель экспедиции А.М. Микляев, с 1985 г. по 1986 г. - А.Н. Мазуркевич). По итогам проведённых работ было выделено три разновременных культурных слоя: слой А (материалы сертейской культуры), В (руднянская культура) и С (остатки стоянки второй половины II тыс. до н.э.). В слое опесчаненного сапропеля с включе- нием угольков - в культурном слое В - помимо фрагментов керамики, каменных артефактов было обнаружено 12 изделий и их фрагментов из кости (рис. 1: 16-26) [14]. Компактность их залегания позволяет утверждать, что это был единовременный комплекс, относящийся к руднянской археологической культуре.

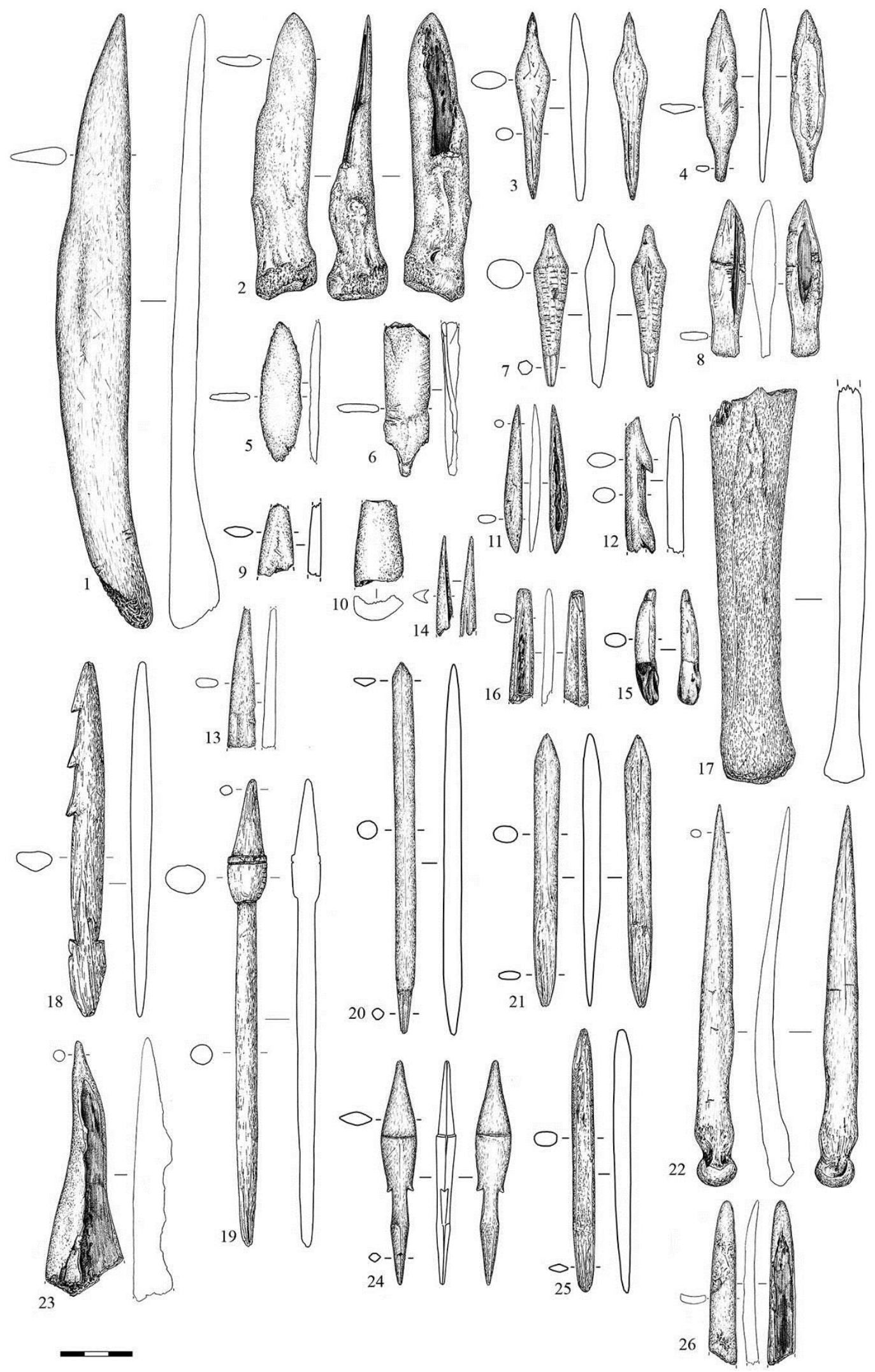

Рисунок 1 - Изделия из кости, рога и зубов. 1-15- Сертея X; 16-26- Рудня Сертейская.

1, 2- ножи; 3, 4, 7, 9, 19-21, 24, 25- наконечники стрел; 5, 6, 8- заготовки; 11- остриё; 12 - зубчатое остриё; 15- подвеска; 13, 22, 23 - проколки; 18- наконечник остроги; 10, 16, 26- фрагменты изделий со следами обработки; 14, 17- без следов обработки и использования (рис. А.А. Малютиной) 
Поселение Сертея $\mathbf{X}$ было открыто в 1986. Культурные слои памятника расположены на западной оконечности суходола, обращенного к старице реки Сертейки, и залегают как на минеральном берегу, так и в толще озёрно-болотных отложений [15]. Раскопки памятника производились с 1986 г. по 1999 г. (раскопки проводились под руководством А.Н. Мазуркевича). Нижние слои памятника (слои А - 1,2 , 3), приуроченные к озёрно-болотным отложениям атлантического периода, являются самыми ранними. Здесь, в слое синеватого опесчаненного сапропеля, были найдены фрагменты сосудов, относящиеся к керамическим фазам «a», «a-1», «b», «b-5» (сертейская культура) [16, с. 75]. Из этих же культурных прослоек происходят 15 изделий из кости, рога, зубов (рис. 1: 1-15), относящиеся к поздним этапам сертейской археологической культуры. На суходольной части памятника, в целом отличающейся сложной стратиграфической картиной материальных остатков разного времени (соотносятся с более поздними керамическими фазами «b», «c»), костяного и рогового инвентаря найдено не было, т.к. в этих слоях органические материалы не сохраняются.

\section{Выбор сырья}

Согласно данным фаунистического анализа, среди промысловых животных преобладали крупные копытные - лось, кабан, олень, тур. Объектом промысла были и такие пушные звери, как куница (чьи кости преобладают), бобр, волк, выдра, хорёк, шкуры которых, вероятно, использовались в быту. Основным мясным животным в раннем неолите был лось. Вторым по значимости - кабан. Анализ возрастных категорий забиваемых животных показал, что промысел на них вёлся круглый год. Охота на птиц в раннем неолите велась в меньшей степени (были определены кости кряквы, свиязи и серой куропатки) [17, с. 144-146].

В качестве сырья для изготовления предметов утилитарного и неутилитарного характера использовались в основном трубчатые кости лося, кабана, медведя (фаунистические определения к.б.н. М.В. Саблина). В единственном случае изделие выполнено из рога и на резце лося. В большинстве случаев степень сработанности не позволяет сказать, к какому виду принадлежала то или иное изделие и какая это часть скелета животного.

\section{Технология, функиия, тип}

Технико-морфологический анализ следов на поверхности изделий из кости и рога позволил выявить следующие особенности. В качестве заготовок использовались расколотые и расщеплённые вдоль и поперёк трубчатые кости, фрагменты рога лося. Вероятно, заготовки из трубчатых костей также извлекались по предварительно вырезанным пазам, но самих пазов не сохранилось, что естественно при тщательной последующей обработке сырья. Заготовки обрабатывались строганием, скоблением, функциональные элементы гарпунов и острог аккуратно вырезались. Готовые изделия тщательно шлифовались и полировались. В единственном случае на поверхности целого наконечника стрелы (рис. 1: 19; рис. 2: $3)$, под его головкой, была отмечена полоска (меньше 1 см в ширину) кольцевых регулярных линейных макроследов (борозд), оставшихся, скорее всего, в результате придания (с помощью абразива) гладкой округлой формы насаду наконечника. Ниже по черешку эти следы снивелированы полировкой (и дальнейшим использованием).

Типологически и функционально материалы стоянки Сертея X можно разделить на следующие категории. Два целых ножа, один (рис. 1: 2) из которых изготовлен из лучевой кости медведя. В данном случае один эпифиз был удалён, диафиз не до конца расколот вдоль и подработан строганием, скоблением и тщательной шлифовкой поверхности. Поверхность рабочей части изделия имеет умеренный блеск, по граням мягко скруглена (притуплена). Боковые поверхности отличаются повышением блеска - заполировкой. Поверхность всего острого конца покрыта многочисленными разнонаправленными линейными микроследами. По боковым граням и примыкающим к ним участкам микроследы располагаются, главным образом, перпендикулярно к основной оси орудия. От острого кончика царапины отходят продольно. Другой нож (кинжал) изготовлен из ребра лося (рис. 1: 1). Суставная часть кости частично срезана. На поверхности в этом месте сохранились поперечные насечки, которыми, судя по всему, примерялись, в каком месте отрезать этот конец, но потом всё-таки оставили эту часть и в итоге под острым углом удалили сустав. Следов подработки, в результате которой был заострён кончик ребра, не сохранилось. Поверхность тщательно зашлифована, заполирована. Рабочее лезвие асимметричное, сильно затупленное в результате работы. Кончик острия округло сглажен, тупой. Плоскость лезвия имеет микрозаполировку, покрыта многочисленными, чаще перпендикулярными к кромке, микро- и макроцарапинами разной длины, охватывающими изделие вплоть до кончика (рис. 2: 2). Судя по сильному износу, орудие долго использовалось. В обоих случаях разнонаправленность линейных следов говорит о сложной кинематике движения при работе с орудиями. Характер самих линейных следов и округлый микрорельеф рабочей поверхности свидетельствует о работе по мягким материалам (шкурам).

В единственном экземпляре в материале стоянки Сертея X представлен фрагмент проколки (рис. 1: 13) из боковой метаподии лося. Один конец кости был заточен, но поверхность изделия сильно эродирована, поэтому самих следов строгания не сохранилось. Микроследы использования также не были обнаружены.

Одно остриё (рис. 1: 11), заготовкой для которого послужил фрагмент трубчатой кости, является, скорее всего, элементом составного изделия. На гранях широкого, прямоугольного в сечении, конца предмета сохранились следы строгания. На противоположном остром конце, круглом в сечении, технологических следов практически не сохранилось. Поверхность острого конца отличается интенсивным блеском, микрорельеф мягко сглажен, а тонкие линейные следы располагаются в виде разнонаправленных единичных линий и перекрестий. Широкий плоский конец следов использования не имеет. Этот конец изделия был вставлен в рукоять (или черешок), тогда как острый кончик являлся рабочим. Характер следов утилитарного износа позволяет предположить, что это были мягкие материалы, однако реконструкция конструктивных особенностей орудия и способов его использования затруднена. 

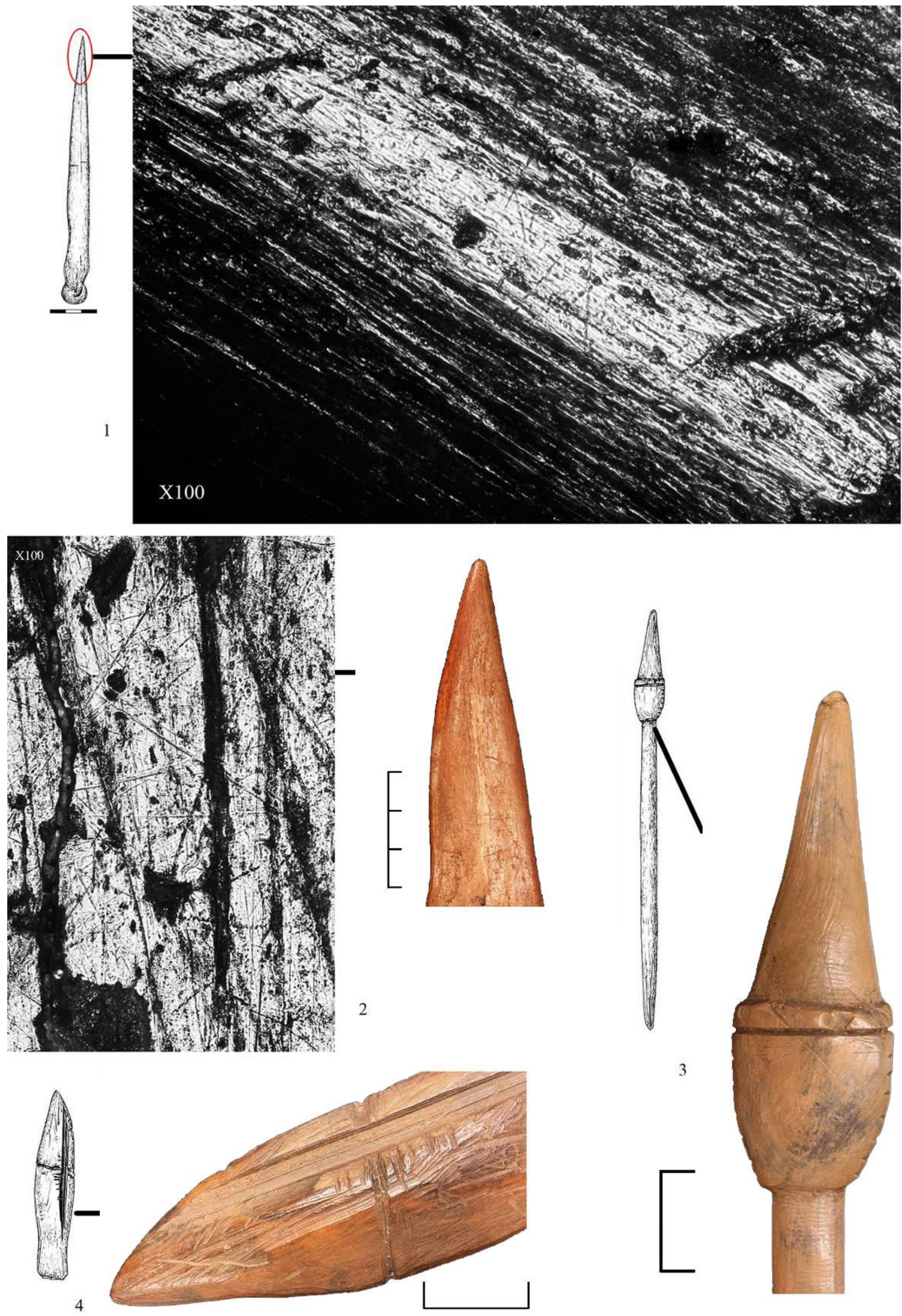

Рисунок 2 - Изделия из кости.

1 - Рудня Сертейская. Микрофотография следов использования (прокалывание шкур)

на рабочем конце проколки (ув. ×100); 2- Сертея Х. Микрофотография следов использования

(разделка туш животного, подготовка шкур) на рабочем конце ножа (ув. ×100); 3- Рудня Сертейская. Макрофотография следов обработки (абразивная шлифовка) на насаде наконечника стрелы; 4- Сертея X.

Макрофотография технологических следов на заготовке наконечника стрелы (фото А.А. Малютиной)

Фрагмент зубчатого острия (1 экз., рис. 1: 12) изготовлен из стенки трубчатой кости. На поверхности хорошо сохранились следы строгания и резания. К промысловому инвентарю также относятся нако- нечники стрел. Один наконечник с коротким, круглым в сечении, коническим остриём, овальным в сечении утолщением в верхней половине изделия и коническим, круглым в сечении насадом (рис. 1: 3). 
Другой (рис. 1: 7) - роговой, также короткий наконечник стрелы с коническим, круглым в сечении, коротким остриём, круглым в сечении утолщением в верхней половине изделия, круглым в сечении туловом и гранёным насадом. По утолщению и тулову сделан орнамент в виде полосок из коротких, параллельных друг другу, поперечных линий. Один листовидный наконечник из трубчатой кости (рис. 1: 4) с прямоугольным в сечении насадом. Также в единственном экземпляре определён линзовидный в сечении фрагмент острия наконечника стрелы (рис. 1: 9) иного морфологического облика, нежели вышеописанные. Фрагмент кальцинированный. Три изделия из трубчатых костей определены как заготовки наконечников стрел (рис. 1: 5, 6, 8; рис. 2: 4) разной степени обработки.

В единственном экземпляре представлена подвеска из резца лося (рис. 1: 15). В корневой части зуба прорезан полу кольцевой паз для крепления нити. Иных следов обработки не выявлено.

Инвентарь стоянки Рудня Сертейская по своему характеру немного отличается от материала Сертеи $\mathrm{X}$. Так, основная категория изделий - наконечники стрел (5 экз.; рис. 1: 19, 20, 21, 24, 25). Все сделаны из кости. Три игловидных наконечника с морфологическими различиями между собой. Один, с уплощённым в сечении остриём, длинным, овальным в сечении, туловом и уплощённым в сечении насадом (рис. 1: 21). На блестящей поверхности изделия сохранились выразительные следы продольного строгания. На кончике острия незначительный скол (результат использования). Другой наконечник имеет сохранность хуже - следов обработки не сохранились (рис. 1: 20). Наконечник имеет треугольное в сечении остриё, длинное, круглое в сечении, тулово и оформленный гранями короткий насад. Третий игловидный наконечник имеет овальное в сечении остриё, длинное, овальное в сечении, тулово и ромбовидный в сечении насад (рис. 1: 25). Поверхность предмета, в месте перехода тулова наконечника в насад, имеет выраженную затёртость - результат его крепления в древко, а кончик острия притуплён. Ещё один наконечник (рис. 1: 19) с коническим круглым в сечении остриём, с кольцевой нарезкой по овальному в сечении утолщению и длинным, круглым в сечении, игловидным насадом. Овальная головка острия орнаментирована тремя полосками из семи или восьми параллельных друг другу, поперечных к основной оси изделия насечками. Стоит отметить, что здесь же был найден деревянный наконечник стрелы (из сосны), не более 8 см. в длину, по своим морфологическим особенностям близкий к вышеописанному костяному наконечнику И, наконец, небольшой наконечник (рис. 1: 24) с ромбовидным в сечении остриём, с симметричными шипами на концах, прямоугольным в сечении туловом и гранёным насадом. На обеих сторонах острия наконечника имеются симметричные друг другу выступы. На поверхности сохранились следы строгания и скобления. Кончик острия незначительно притуплён. К предметам охоты также относится единственный наконечник остроги (рис. 1: 18), заготовкой для которого послужила пластина из диафиза трубчатой кости. По одному боковому краю изделия вырезаны три зубца, насад, уплощённый в сечении, лопатко- видной формы с вырезанной закраиной на одной боковой грани. Кончик остроги значительно затуплён (результат использования?).

Из орудий имеются две проколки (рис. 1: 22), одна из которых на боковой метаподии лося с незначительной заточкой острого конца. Следы строгания перекрыты умеренным утилитарным износом в виде ровного блестящего микрорельефа поверхности в совокупности с тонкими разнонаправленными линейными следами (рис. 2: 1), иногда в виде перекрестий. Кончик проколки округлый. Второе изделие выполнено на осколке локтевой кости кабана (рис. 1: 23). Поверхность сильно эродирована, технологических следов не сохранилось. На круглом в сечении острие сохранились небольшие участки с утилитарным износом: умеренный блеск, разнонаправленные тонкие линейные следы. Кончик изделия имеет значительную деформацию, не связанную с использованием. В обоих случаях износ связан с работой по мягким материалам - прокалыванием шкур.

Есть в материалах обеих стоянок предметы со следами обработки строганием, следы использования при этом выявлены не были (рис. 1: 10, 16, 26). Во всех случаях заготовками служили продольно расколотые трубчатые кости. Ранее к предметам со следами обработки относились: фрагмент ребра лося (рис. 1: 17) со стоянки Рудня Сертейская и зубная кость (клюв) птицы с Сертеи X (рис. 1: 14), но проведённый нами анализ технологических и функциональных следов не выявил.

\section{Аналогии и контекст}

Согласно данным комплексных исследований Сертейского микрорегиона в целом, такие памятники с ранненеолитической керамикой, как Рудня Сертейская и Сертея X, располагались на мысах палеоозера, при впадении в него древних ручьёв, озёрных проток или на острове. Такое расположение памятников предполагает занятие рыболовством, охотой в широколиственных лесах, т.е. в зоне летнего обитания животных [18] и птиц [17, с. 144-146]. Так, стоянка Рудня Сертейская, скорее всего, была местом временного обитания на период сезонной охоты, а основным поселением являлось поселение Сертея X, на котором были открыты остатки жилых конструкций с керамическим материалом различных фаз [10, c. 66]. В пользу этого говорит и набор изделий из кости и рога с памятника Сертея $\mathrm{X}$, где мы имеем готовые орудия (ножи для разделки туш животных, проколку для подготовки шкур к использованию), промысловый инвентарь (зубчатое остриё, наконечники стрел и их заготовки), украшения (подвеска из резца лося). Данный набор (пусть и немногочисленный), как нам кажется, отражает одну из основных сфер хозяйственно-бытовой жизни древних охотниковсобирателей. Наличие заготовок наконечников стрел, фрагментов изделий со следами обработки может свидетельствовать, что обработка сырья, изготовление орудий происходило непосредственно на памятнике. Тогда как на стоянке Рудня Сертейская из предметов бытового характера только две проколки, а основной категорией являются орудия промысла наконечники стрел и наконечник остроги (для ловли с берега?), которые, скорее всего, были потеряны в процессе охоты. 
Стоит отметить, что типологически наконечники стрел с поселения Сертея X и со стоянки Рудня Сертейская различаются, при этом близкие аналогии и тем и другим мы находим на памятниках эпохи раннего неолита современной Латвии, на Лубанском озере [19, fig. LXXVII: 8, fig. LXXVII: 2, fig. LXXV: 17, fig. LXIII: 22, 23, fig. LXXXIV: 3; 20, fig. 8: 1], где в это время существовала нарвская ранненеолитическая культура. Здесь же мы находим аналогии и длинному ножу из ребра лося с памятника Сертея $\mathrm{X}$ [19, fig. XLVII: 1]. Скорее всего, мы имеем несколько «волн» движений древнего прибалтийского населения в верховья Западной Двины.

В связи с этим интерес вызывают наблюдения относительно каменного инвентаря, полученного при раскопках стоянки Рудня Сертейская. Исследователи полагают, что люди, пришедшие сюда, только начали адаптироваться к местным условиям (к местному сырью), о чём свидетельствует, например, получение из непластичного кремня пластин, выбор (и перемещение их на памятник) кусков известняковых пород с возможным содержанием кремневых конкреций $[14$, c. 18$]$.

\section{Заключение}

Костяной и роговой инвентарь ранненеолитических памятников Сертейского микрорегиона ДнепроДвинского междуречья отражает и дополняет сложную картину проникновения и формирования на этих территориях различных культурных традиций. Люди, пришедшие сюда, хорошо знали, какое сырьё использовать для изготовления орудий, что из него можно получить и как эффективно использовать. При этом позднее, в эпоху среднего - позднего неолита, мы имеем здесь иную традицию обработки костяного и рогового сырья, иной характер поселений и связанный с этим набор орудий из кости, рога, зубов.

\section{Список литературы:}

1. Микляев А.М. Памятники Усвятского микрорайона. Псковская область // Археологический сборник Государственного Эрмитажа. № 11. Л., 1969. C. $18-40$.

2. Mazurkevich A.N., Dolukhanov P.M., Shukurov A.M., Zaitseva G.I. Pottery-making revolution in Northern Eurasia // Man and Environment in Pleistocene and Holocene: Evolution of waterways and Early Settlement of Northern Europe: International conference. $\mathrm{SPb}, 2006$. P. 25-66.

3. Мазуркевич А.Н. О раннем неолите ЛоватскоДвинского междуречья // Петербургский археологический вестник. № 9. СПб., 1994. С. 77-84.

4. Микляев А.М., Мазуркевич А.Н. Опыт интерпретации некоторых орнаментальных традиций посуды усвятской культуры // Проблемы археологии. Вып. 3. СПб.: Изд-во СПбГУ, 1994. С. 78-84.

5. Mazurkevich A., Dolbunova E. The oldest pottery in hunter-gatherer communities and models of Neolithisation of Eastern Europe // Documenta Praehistorica XLII. Ljubljana University Press. Ljubljana, 2015. P. 14-66.

6. Мазуркевич А.Н., Зайцева Г.И., Кулькова М.А., Долбунова Е.В., Семенцов А.А., Ришко С.А. Абсолютная хронология неолитических древностей Днепро-Двинского междуречья VII-III тыс. до н.э. // Радиоуглеродная хронология эпохи неолита Восточной Европы VII-III тыс. до н.э. Смоленск: Свиток. 2016. C. 317-356.
7. Семёнов С.А. Первобытная техника // Материалы и исследования по археологии СССР. № 54., М. - Л., 1957. 239 с.

8. Семёнов С.А., Коробкова Г.Ф. Технология древнейших производств. Л., 1983. 256 с.

9. Коробкова Г.Ф., Шаровская Т.А. Экспериментальное изучение костяных орудий каменного века // Каменный век европейских равнин: материалы междунар. конф. Сергиев Посад, 2001. С. 182-191.

10. Maigrot Y. Ivory, Bone and Antler Tools Production Systems at Chalain 4 (Jura, France), Late Neolithic Site, 3rd Millennium // Hooves to Horns, from Mollusc to Mammoth, Manufacture and Use of Bone Artefacts from Prehistoric Times to the Present, 4th Meeting of the Worked Bone Research Group, Tallinn, 2003, Talinn, Ajaloo Instituut-Tartu Ülikool (Muinasaja teadus 15), 2005. Р. 113-126.

11. Дэвид Е. Изделия из кости и рога мезолитических слоёв стоянки Замостье 2: технологический подход // Каменный век Европейских равнин: материалы междунар. конф. Сергиев Посад, 2001. С. 292-303.

12. Жилин М.Г. Костяная индустрия мезолита лесной зоны Восточной Европы. М., 2001. 326 с.

13. Малютина А.А., Саблин М.В. Выбор сырья и первичная обработка костяного и рогового материала торфяниковой неолитической стоянки Усвяты IV // Записки ИИМК РАН. СПб.: Изд-во «Дмитрий Буланин», 2014. С. 21-31.

14. Мазуркевич А.Н., Микляев А.М. О раннем неолите междуречья Ловати и Западной Двины // Археологический сборник Государственного Эрмитажа. Вып. 33. СПб., 1998. С. 7-33.

15. Мазуркевич А.Н., Еремеев И.И., Короткевич Б.С., Фурасьев А.Г., Зайцева Г.И., Лисицын С.Н. Работы Северо-Западной археологической экспедиции в Ловатско-Двинском междуречье // Отчётная археологическая сессия за 1996 г. Тез. док. СПб., 1997. С. 34-37.

16. Долбунова Е.В. Древнейшие керамические традиции в Днепро-Двинском междуречье: 7-6-го тыс. до н.э.: дис. ... канд. ист. наук: 07.00.06. СПб., 2015. $380 \mathrm{c}$.

17. Саблин М.В., Пантелеев А.В., Сыромятникова Е.В. Археозоологический анализ остеологического материала из неолитических свайных поселений Подвинья: хозяйство и экология // Труды Зоологического института РАН. 2011. Т. 315, № 2. С. 143-153.

18. Верещагин Н.К., Русаков О.С. Копытные северо-запада СССР. Л.: Наука, 1979. 309 с.

19. Vankina L. The collection of Stone Age bone and antler artefacts from lake Lubana. Catalogue. Riga, №I. M. S. 1999. 290 p.

20. Loze I. The Early Neolithic at the IČA settlement site (lake Lubana depression) // Lietuvos archeologija, T. 19. Vilnius, 2000. P. 203-220.

Исследование проведено в рамках выполнения программы фундаментальных научных исследований государственных академий наук (или ФНИ ГАН) по теме государственной работы: № 01842018-0006. "Производство и использование орудий труда в палеолите, неолите и эпоху бронзы (технологическое, трасологическое и экспериментальное изучение археологических материалов)». 


\section{BONE AND ANTLER IMPLEMENTS \\ OF THE EARLY NEOLITHIC DNEPR-DVINA INTERFLUVE SETTLEMENTS: TECHNOLOGICAL AND FUNCTIONAL FEATURES, CONTEXT}

(C) 2018

Malyutina Anna Andreevna, junior researcher of Experimental-Traceology Laboratory Institute of History of Material Culture of the Russian Academy of Sciences (Saint Petersburg, Russian Federation)

Abstract. In this paper we consider the results of the use-wear analysis of the bone and antler implements received as a result of excavation of the Early Neolithic settlements on the territory of Dnepr-Dvina interfluve. This kind of research is conducted for this category of archaeological material for the first time. For the analysis we have selected 27 bone, antler and teeth items occurring from two settlements of the Serteysky microregion - Serteya X and Rudnya Serteyskaya. The good preservation of items has allowed us to study macro- and microtraces connected with technology of processing of raw materials and receiving products, ways of usage of finished utilitarian and not utilitarian character items. The following categories of implements have been marked out: knives, awls, pendants, spear-heads, arrowheads, barbed points, preforms, fragments of items with processing traces. The obtained information is correlated to other materials of settlements - ceramics, stone artifacts, economic and cultural characteristic of settlements in general. Ceramic traditions in upper courses of the Western Dvina belong to 7 millennium BC. The earliest ceramic traditions are combined in Serteyskaya archaeological culture. Later, in materials of the Early Neolithic sites influence of Early Neolithic cultures of East Baltics is traced. As a result, on the territory of Podvinya the Rudnyanskaya Early Neolithic culture is formed.

Keywords: Early Neolithic; Serteyskaya culture; Rudnyanskaya culture; Dnepr-Dvina interfluve; Narva culture; use-wear analysis; choice of raw material; technology of processing; preliminary treatment; preform; secondary treatment; macrotraces; microtraces; function; typology; category; reconstruction; ancient hunting and fishing.

\section{ПЕТРОГРАФИЧЕСКИЙ АНАЛИЗ КЕРАМИКИ НОВОСВОБОДНЕНСКОЙ КУЛЬТУРЫ ИЗ ПОГРЕБЕНИЙ В КУРГАННОМ МОГИЛЬНИКЕ «КЛАДЫ»}

(C) 2018

Резепкин Алексей Дмитриевич, кандидат исторических наук, старший научный сотрудник отдела Центральной Азии и Кавказа

Институт истории материальной культуры РАН (г. Санкт-Петербург, Российская Федерация)

Аннотащия. Морфологический анализ керамики новосвободненской культуры до сих пор не проводился. В данной работе представлен анализ 19 фрагментов сосудов из погребений курганного могильника «Клады». В результате было выяснено, что состав глиняной массы, применяемой в изготовлении керамики, был весьма разнообразен: как цельные виды глин - известняковые, монтмориллонитовые, гидрослюдистые, так и в их разнообразных комбинациях - еще шесть вариантов. Причем почти половина сосудов (девять) была изготовлена из известняковых и монтмориллонитовых глин. Разнообразен и состав примесей - песок, шамот, известняк и дресва, также в различных смешанных вариантах. Меньше всего было фрагментов без примесей, всего четыре. Сосуды подвергались как окислительному обжигу, так и восстановительному. Комбинированному, окислительно-восстановительному обжигу были подвергнуты всего три экземпляра. Проведен сравнительный анализ майкопской и новосвободненской керамики. Таким образом, данный способ исследования керамики показал, что носители новосвободненской культуры обладали большим опытом керамического производства, что позволяло им использовать широкий ассортимент глин, причем в их разнообразных комбинациях, и способов обжига в изготовлении керамики.

Ключевые слова: Северный Кавказ; эпоха ранней бронзы; четвертое тысячелетие; Майкопская культура; новосвободненская культура; керамика; морфологический анализ; виды глин; примеси керамики; восстановительный обжиг; окислительный обжиг; петрографический анализ; технология изготовления керамики.

До сих пор керамика новосвободненской культуры рассматривалась с точки зрения типологии [110]. Следующий этап изучения керамического комплекса культуры, как представляется, должен включать в себя технологию изготовления и петрографический анализ, что позволит более обоснованно показать не только типологические, но и иные параметры отличия новосвободненской керамики от майкопской. В данной работе впервые представлен петрографический анализ новосвободненской керамики из погребений курганного могильника «Клады».

Обр. К-1. Плотная, тонкостенная (7 мм) керамика черного цвета, лощеная (рис. $1: K-1-1-3$ ).
Состав: глины известковые, жирные, кластического (обломочного) материала - 5-10\%, кварц, полевой шпат.

Отощитель: дробленый известняк (20\%), размер 0,5-1 мм, шамот (10\%) (высушенная ожелезненная глина), отдельные углистые частицы (0,7-1,5 мм), песок кварц полевошпатового состава $(40 \%)(0,15-$ 0,5 мм). Пористость: округлые поры (5\%), размером 2-3 мм. Температура обжига $800-850^{\circ} \mathrm{C}$ (остатки карбоната, невыгоревшей органики, угля), обжиг восстановительный, кратковременный.

Обр. К-2. Плотная, керамика серого цвета, лощеная с внешней поверхности (рис. $1: K-2-1-3$ ). 